\title{
The Quality of Life in Children with Hemophilia in Bali
}

\author{
I Gusti Ayu Trisna Windiani*, Putu Antara, Soetjiningsih, I Gusti Agung Ngurah Sugitha Adnyana, \\ Ketut Ariawati
}

Department of Child Health, Udayana University School of Medicine, Sanglah Hospital, Denpasar, Indonesia

Email address:

trisnawindianidr@yahoo.co.id (I G. A. T. Windiani)

${ }^{*}$ Corresponding author

\section{To cite this article:}

I Gusti Ayu Trisna Windiani, Putu Antara, Soetjiningsih, I Gusti Agung Ngurah Sugitha Adnyana, Ketut Ariawati. The Quality of Life in Children with Hemophilia in Bali. American Journal of Pediatrics. Vol. 6, No. 4, 2020, pp. 459-462. doi: 10.11648/j.ajp.20200604.22

Received: March 4, 2020; Accepted: September 15, 2020; Published: November 11, 2020

\begin{abstract}
Hemophilia in children adversely affects both their psychological as well as their physical health. It is important to understand more about the quality of life $(\mathrm{QoL})$ in this patient population. The aim of this study was to assess health-related QoL of children with hemophilia in Bali. A cross sectional study was carried out on children with hemophilia in Bali. Data on the quality of life was collected through questionnaires using PedsQL Generic Core Scales version 4.0 inventory. Independent $t$ test was used to analysis data. Child reports showed mean score on each domain function (physical, emotional, social and school function) in hemophilia group compared to healthy children group were 71.8 vs $97.9,81.4$ vs $94.5,85.0$ vs 97.5 , and 73.1 vs 94.5 , respectively. Parent-proxy reports showed mean scores on each domain function (physical, emotional, social, and school function) in hemophilia group compared to healthy children group were 73.3 vs $97.3,79.5$ vs $94.5,80.2$ vs 97.5 , and 67.4 vs 89.8 , respectively. Total PedsQL score in hemophilic children and healthy group showed a significant difference in both reports (child report; $\mathrm{p}<0.05$, with the mean difference was -18.7 with $95 \% \mathrm{CI}$ of -25.9 to -13.6 and parent-proxy report; $\mathrm{p}<0.05$ the mean difference was -19.8 with $95 \%$ CI of -25.9 to -13.5 ). Hemophilia has a negative impact on the children's daily life. Hemophilia group reported poor quality of life as regards the physical, emotional, social, school functioning domains, and total quality of life than healthy children group.
\end{abstract}

Keywords: Children, Hemophilia, Quality of Life

\section{Introduction}

Hemophilia is a rare, chronic, the hereditary bleeding disorder caused by a defective factor VIII or factor IX (plasma clotting factor), leading to impaired clotting characterized by spontaneous bleeding and excessive bleeding after surgery or trauma [1]. It is an X chromosomelinked resessive, inherited disease primarily affecting males [2]. Based on data from HMHI (Himpunan Masyarakat Hemofilia Indonesia) in 2012, children with hemophilia in Indonesia was approximately 1410 children, but World Foundation Hemophilia (WHF) estimated 20.000 children affected hemophilia. There are two most common forms of hemophilia, hemophilia A and hemophilia B $[3,4]$.

Clinically, it is useful to classify them according to the measured factor VIII and IX activity in the plasma as: severe $<1 \%$, moderate 1 to $5 \%$, and mild $>5$ to $25 \%$. Children with severe hemophilia have frequent, spontaneous bleeding episodes that usually involve major joints, muscles, or soft tissues and may lead to residual morbidity. These morbidity indicates that hemophilic children had a diminished quality of life $[5,7]$.

World Health Organization (WHO) defines QoL as "the individual's perception of their position in life in the context of the culture and value systems in which they live and in relation to their goals, expectations, standards and concerns", in other words, a global view that considers many dimensions of the human beings.

Quality of life measurement assess important aspects of health include the effect of a health condition on the child's daily activities, physical symptoms, social interactions, and emotional wellbeing. Quality of life in children with chronic condition has received increasing attention in recent years especially for frequent pediatric health condition such as leukemia or asthma.

However, the QoL of children with hemophilia has been 
largely neglected. It is important to understand more about QoL in this patient population [6, 7].

Studies showed that there is a consistent relationship between hemophilic children and the perception of low QoL. Taha and Hassan in 2014 found QoL in children with hemophilia in physical function, feeling, and school function significantly lower than normal children [7].

Information data or research about the QoL of children with hemophilia in Bali region has never been reported until today.

The aim of this study was to assess health-related quality of life in Bali hemophilic children using a PedsQL version 4.0 questionnaire. The results of this study can be used as the basic data for the further research.

\section{Materials and Method}

The study was a cross sectional study on children with hemophilia in Bali based on data obtained from data of HMHI region Bali, comparing with healthy children. This study uses a significance level of $p<0.05$ and power of $80 \%$, obtained calculation of sample size of at least 22 of hemophilia children and 22 of healthy children. The target populations were children with hemophilia. The accessible population of this study were children with hemophilia in Bali. The inclusion criteria are: (1) the age two to eighteen years and had been conclusively diagnosed with hemophilia by factor VIII or IX testing, (2) the parents are willing to participate in the study and signed an informed consent form. The exclusion criteria are: (1) with chronic disease, (2) with anomaly congenital, and (3) medical records or data was incomplete or lost.

The PedsQL 4.0 Indonesian version was used to assess health-related quality of life in this study. This is a validated 23 item questionnaire for children aged 2-18 years, administered as either a child self-report or a parent proxyreport $[8,9]$.

In this study, data on the QoL was collected through questionnaires using PedsQL Generic Core Scales version 4.0 inventory of the QoL of children aged 2 to 18 years old. In brief, the PedsQL comprises four subscales: physical ( 8 items), social (5 items), emotional (5 items), and school functioning ( 5 items). The instructions ask how much of a problem each item has been during the last month. A fivepoint response scale in used $(0=$ never, $1=$ almost never, $2=$ some times, $3=$ often, $4=$ always $)$.

Items were reverse-scored and linearly transformed to a 0 100 scale $(0=100,1=75,2=50,3=25,4=0)$, so that higher scores indicate better quality of life. A total scale score, derived by the mean of all 23 items, was calculated to provide an overall measure of the QoL. 8.

Hemophilia A is children with hereditary bleeding disorder caused by a defective of factor VIII. Hemophilia B is children with hereditary bleeding disorder caused by a defective of factor IX.

Severity of hemophilia was divided into severe $(<1 \%)$, moderate ( 1 to $5 \%$ ), and mild ( $>5$ to $25 \%$ ) according to the measured factor VIII or IX level in the plasma. Healthy children is male siblings or close relationship with hemophilia children aged 2 to 18 years.

Parent education was divided into high and low educated. High educated if parents have completed senior high school level and more. Low educated if parents have less than senior high school level.

Parent income was divided into low and high income. High income if parents had more than minimum regional salary of Bali province on 2016 (Rp 1.800.000,-) and low income if parents had less than minimum regional salary of Bali province on 2016 ( $R p$ 1.800.000). 9.

All statistical analyses was performed by using SPSS. Descriptive statistics was used to summarize characteristics data. To explore differences in PedsQL score between different groups, independent sample t tests (two groups) was used.

Ethical clearance was obtained from Research Ethics Committee of Medical Faculty Udayana University/Sanglah Hospital Denpasar no. 1970/UN. 14.2/KEP/2017.

\section{Results}

The characteristics of participating children are shown in Table 1 . In this study, 22 of male children were hemophilia, while 22 were male healthy children. Median age of hemophilia group were 10 years old and in healthy children were 8 years old. There were 4 hemophilia and 2 healthy children aged 2 to 4 years old. Out of 22 patients, 17 had hemophilia A and 5 had hemophilia B. According to severity of the hemophilia, no patient had mild hemophilia, 13 patients $(59.1 \%)$ had moderate hemophilia, and 9 patients $(40.9 \%)$ had severe hemophilia. The educational level obtained fathers and mothers in both groups with most highly educated $(86.4 \%)$.

The mean values PedsQL 4.0 score of child report and parent-proxy report of hemophilia group compared to healthy children are presented in Table 2 and Table 3. Child reports for the 2 to 4 year age group was not available, so data analyzed about 18 children in hemophilia group and 22 children in healthy group. Child reports showed mean score on each domain function (physical, emotional, social and school function) in hemophilia group compared to healthy children group were 71.8 vs $97.9,81.4$ vs $94.5,85.0$ vs 97.5 , and 73.1 vs 94.5 , respectively.

Parent-proxy reports showed mean scores on each domain function (physical, emotional, social, and school function) in hemophilia group compared to healthy children group were 73.3 vs $97.3,79.5$ vs $94.5,80.2$ vs 97.5 , and 67.4 vs 89.8 , respectively.

Child and parent-proxy report showed the mean (SD) score of total PedsQL in hemophilia group compared to healthy children group were 77.3 (12.1) vs 96.0 (4.3) with mean difference was $-18.7,95 \%$ CI of -25.9 to $-13.6(\mathrm{p}<0.05)$ and 75.7 (13.7) vs 95.5 (4.1) with mean difference was $-19.8,95 \%$ CI of -25.9 to $-13.5(p<0.05)$, respectively. 
Table 1. Subjects' characteristics.

\begin{tabular}{lll}
\hline & Hemophilic & Healthy children \\
\cline { 2 - 3 } & $\mathbf{n = 2 2}$ & $\mathbf{n}=\mathbf{2 2}$ \\
\hline Age, median (range), years & $10(4$ to 18$)$ & $8(3$ to 16$)$ \\
Gender, n (\%) & $22(100)$ & $22(100)$ \\
Male & $17(77.3)$ & 0 \\
Hemophilia A, n (\%) & $5(22.7)$ & 0 \\
Hemophilia B, n (\%) & & \\
Severity (factor level) & 0 & 0 \\
Mild (>5-25\%) & $13(59.1)$ & 0 \\
Moderate (1-5\%) & $9(40.9)$ & 0 \\
Severe (<1\%) & $7(31.8)$ & $7(31.8)$ \\
Mother's education, n (\%) & $15(68.2)$ & $15(68.2)$ \\
Low education & & \\
High education & $3(13.6)$ & $3(13.6)$ \\
Father's education, $\mathrm{n}(\%)$ & $19(86.4)$ & $19(86.4)$ \\
Low education & & $4(18.2)$ \\
High education & $5(22.7)$ & $18(81.8)$ \\
Parent's income, $\mathrm{n}(\%)$ & $17(77.3)$ & \\
Low income & & \\
High income & & \\
\hline
\end{tabular}

Table 2. The Peds $Q L 4.0$ child report: hemophilia and healthy children

\begin{tabular}{|c|c|c|c|c|c|c|c|c|}
\hline \multirow{3}{*}{ QoL } & \multicolumn{4}{|l|}{ Group } & \multirow{3}{*}{ Mean dif } & \multirow{3}{*}{$\mathbf{t}$} & \multirow{3}{*}{$\mathbf{p}$} & \multirow{3}{*}{$95 \% \mathrm{CI}$} \\
\hline & \multicolumn{2}{|c|}{ Hemophilic } & \multicolumn{2}{|c|}{ Healthy } & & & & \\
\hline & Mean & SD & Mean & SD & & & & \\
\hline Physical function & 71.8 & 21.9 & 97.9 & 2.5 & -26.1 & -5.3 & $<0.001$ & $-36.1-(-16.1)$ \\
\hline Emotional function & 81.4 & 15.1 & 94.5 & 8.4 & -13.1 & -3.3 & 0.002 & $-21.1-(-5.2)$ \\
\hline Social function & 85.0 & 14.6 & 97.5 & 3.4 & -12.5 & -3.7 & 0.001 & $-19.3-(-5.7)$ \\
\hline School function & 73.1 & 14.6 & 94.5 & 7.9 & -21.4 & -5.7 & $<0.001$ & $-29.1-(-13.8)$ \\
\hline Total score & 77.3 & 12.1 & 96.0 & 4.3 & -18.7 & -6.5 & $<0.001$ & $-25.9-(-13.6)$ \\
\hline
\end{tabular}

Table 3. The Peds QL 4.0 parent-proxy report: hemophilia and healthy children

\begin{tabular}{|c|c|c|c|c|c|c|c|c|}
\hline \multirow{3}{*}{ QoL } & \multicolumn{4}{|l|}{ Group } & \multirow{3}{*}{ Mean dif } & \multirow{3}{*}{$\mathbf{t}$} & \multirow{3}{*}{$\mathbf{p}$} & \multirow{3}{*}{$95 \%$ CI } \\
\hline & \multicolumn{2}{|c|}{ Hemophilic } & \multicolumn{2}{|c|}{ Healthy } & & & & \\
\hline & Mean & SD & Mean & SD & & & & \\
\hline Physical function & 73.3 & 21.1 & 97.3 & 3.1 & -24.2 & -5.3 & $<0.001$ & $-33.2-(-14.8)$ \\
\hline Emotional function & 79.5 & 15.6 & 94.5 & 8.2 & -15.0 & -3.9 & $<0.001$ & $-22.6-(-7.4)$ \\
\hline Social function & 80.2 & 15.3 & 97.5 & 3.4 & -17.3 & -5.2 & $<0.001$ & $-24.0-(-10.5)$ \\
\hline School function & 67.4 & 25.5 & 89.8 & 21.5 & -22.4 & -3.1 & 0.003 & $-36.7-(-7.9)$ \\
\hline Total score & 75.7 & 13.7 & 95.5 & 4.1 & -18.7 & -6.5 & $<0.001$ & $-25.9-(-13.5)$ \\
\hline
\end{tabular}

\section{Discussion}

In our study, health-related QoL scores was measured by using PedsQL Generic Core Scales version 4.0 inventory. In repeated reliability and validity tests, the PedsQL has consistently had high reliability scores $(\alpha=0.71-0.89)$ and has also been able to distinguish between healthy children and those with chronic diseases $[10,11]$. Higher score indicating better QoL. The total, physical health, and psychosocial health score for a healthy paediatric population have been determined to be $83.8 \pm 12.7,87.5 \pm 13.5$, and $81.9 \pm 14.1$, respectively [12]. Huang et al. [13] reported that children $<8$ years, the recommended cutoff scores was 77 for major chronic conditions. For children $\geq 8$ years, the cutoff scores was 70 .

Hemophilia children reported poorer QoL as regards the physical, emotional, social, school functioning domains and total QoL than healthy children group, which suggests that hemophilia children has a negative impact on the children's daily life. In our study, child and parent-proxy reports showed scores on each domain function was lower in hemophilia compared to healthy children group. The mean score of total PedsQL lower in hemophilia children group compared to healthy children group, and showed a significant difference in both reports. These findings are consistent with the study that was done by Maricela et al [14] in the Mexico, who stated that hemophilic children groups reported impairment in all QoL.

Children with hemophilia was more likely to experience psychosocial problems than their normal children. Taha and Hasan 7 reported that psychososial factors affecting QoL include coping, social support, and locus of control in contrast to clinical variables, which contribute highly to the explained variance, differing across countries. Many factors like severity of disease, number of bleeding episodes, and type of treatment (prophylactic versus on-demand), which are important predictors, depend on the health care system and specific characteristic of a given country [18, 19]. Hemophilia children, compared with healthy children, were 
found to be significantly more likely to negatively perceived competence. This may be explained by lack of prophylaxis, leading to restriction of children with hemophilia to participate in physical activities [7, 15-18].

Regarding the score on the functioning of the school, the difference was statistically significant in both groups. These findings are consistent with a study in Mexico, Iraq, and Phillippines. They reported a school function of children within hemophilia were significantly lower than the group of healthy children. This seems to prove that having to go to hospital for hemophilia treatment is one of the main reasons that hemophilia children are missing school and this is affecting their quality of life $[14,15,20]$.

The limitation of our study is the use of the PedsQL 4.0. We did not uses disease-specific instruments to assess quality of life of children with hemophilia. We expected to do further research.

Management of hemophilia should include health related quality of life measurements as a parameter of hemophilia outcome. We recommend the use of PedsQL questionnaire as a simple, easy and reliable measurement model for assessment of health related QoL. Better understanding QoL is a key element essential for the treatment for children with hemophilia.

\section{Conclusion}

Hemophilia has a negative impact on the children's daily life. Hemophilia group reported poorer quality of life as regards the physical, emotional, social, school functioning domains and total quality of life than healthy children group.

\section{Funding}

The authors received no financial support for the research, authorship, and/or publication of this article.

\section{References}

[1] Centers for Disease Control and Prevention Hemophilic, Data and Statistics. 2011 (cited 14 April 2013). Available from http://www.cdc.gov/ncbddd/hemophilia/facts.html.

[2] Haffman R, Benz EJ, Shattil SJ. Hematology Basic Principles and Practice. $5^{\text {th }}$ edition. Philadelphia: Churchill Livingstone. 2009.

[3] Salek S, Boban A, Pulanic D. Characteristics of older patient with haemophilia. Hemophilia. 2012: 112-30.

[4] Acharya, S. Hemostasis disorder. In: Lanzkowsky P, editor. Manual of pediatric hematology and oncology. $5^{\text {th }}$ edition. London: Elsevier; 2011: 378-418.

[5] Fischer K, van der Bom JG, van den Berg HM. Health-related quality of life as outcome parameter in haemophilia treatment. Haemophilia. 2003; 9: 75-81.
[6] WHOQOL Group. Development of the WHOQOL: rationale and current status. Int J Mental Health. 1994; 23: 24-56.

[7] Taha MY and Hassan MK. Health-related quality of life in children and adolescents with hemophilia in Basra, Southern Iraq. J Pediatr Hematol Oncol. 2014; 3: 179-84.

[8] Varni JW, Seid M, Rode CA. The PedsQL: measurement model for the pediatric quality of life inventory. Med Care. 1999; 37: 126-39.

[9] Badan Pusat Statistik Propinsi Bali. 2017 (cited 16 August 2017). Available from http://www.bali.bps.go.id.

[10] Poon JL, Zhou ZY, Doctor JN, Wu J, Ullman MM, Ross C et al. Quality of life in haemophilia A: Hemophilia tilization group study Va (HUGS-Va). Haemophilia. 2012; 1-9.

[11] Varni JW, Burnwinkle TM, Seid M. The PedsQL 4.0 as a school population healthmeasure: feasibility, reliability, and validity. Quality of Life Research. 2006; 15: 203-15.

[12] Varni JW, Limbers CA, Burwinkle TM. Impaired healthrelated quality of life in children and adolescents with chronic conditions: a comparative analysis of 10 disease clusters and 33 disease categories/severities utilizing the PedsQL 4.0 Generic Core Scales. Health Qual Life Outcomes. 2007; 5: 43.

[13] Huang IC, Thompson LA, Chi YY, Knapp CA, Revicki DA, Seid M, et al. The linkage between pediatric quality of life and health conditions: establishing clinically meaningful cutoff scores for the PedsQL. Value Health. 2009; 12: 773-81.

[14] Maricela OG, Georgina BR, Miguel IZ. Quality of life perceived by pediatric hemophilia patients and their parents in Mexico. Hemophilia Federation of Mexico. 2012; 15: 233-40.

[15] Bullinger M, von Mackensen S. Psycho-social determinants of quality of life in children and adolescents with hemophilia-a cross-cultural approach. Clini Psychol Psychother. 2008; 15: 164-72.

[16] Tantawy AAG, von Mackensen S, Labib JH, Moftah F, Mansour WAA. Health-related quality of life in Egyptian children and adolescents with hemophilia A. Pediatric Hematology and Oncology. 2011; 28: 222-9.

[17] Mercan A, Sarper N, Inanir M, Mercan HI, Gokalp AS, Zengin E. Hemophilia-specific quality of life index (HaemoQoL and Haem-A-QoL questionnaires) of children and adults: result of single center from Turkey. Pediatric Hematology and Oncology. 2010; 27: 449-61.

[18] Von Mackensen S. Quality of life and sports activities in patients with haemophilia. Haemophilia. 2007; 13: 38-43.

[19] Broderick CR, Herbert RD, Latimer J. Curtins JA. Fitness and quality of life in children with haemophilia. Haemophilia. 2010; 16: 118-23.

[20] Espaldon AMD and Hernandes FG. Health-related quality of life assessment in Filipino children with hemophilia aged 4 to 16 years in a tertiary hospital. J Hematol Thromb Dis. 2014; 2: 133-9. 